\title{
Epidemiology of duodenal ulcer perforation: a study on hospital admissions in Norfolk, United Kingdom
}

\author{
D.S. Canoy \\ A.R. Hart ${ }^{1}$ \\ C.J. Todd ${ }^{2}$
}

\section{From}

Department of Public Health and Primary

Care, University of Cambridge,

Strangeways Research Laboratory,

Cambridge; ${ }^{1}$ School of Medicine, Health

Policy and Practice, University of East

Anglia, and Honorary Consultant in

Gastroenterology, Norfolk and Norwich

University Hospital NHS Trust, Norwich;

${ }^{2}$ School of Nursing, Midwifery and Health

Visiting, University of Manchester Coupland

III, Manchester, UK.

Address for correspondence

Dr. D.S. Canoy, Research Student,

Department of Public Health and Primary

Care, University of Cambridge,

Strangeways Research Laboratory, Worts

Causeway, Cambridge CB1 8RN.

Fax: +44-1223-411609.

E-mail:dc237@cam.ac.uk

\section{Acknowledgements}

Prof. Todd was Director of Health Services Research at University of Cambridge when study was undertaken. Study was partly funded by the NHS Eastern Region Rand D. Authors are grateful for support of Statistics and Information Unit as well as Health Records Library staff of hospitals involved INorfolk and Norwich Health Care NHS Trust (Norwich), James Paget Hospital Healthcare Trust (Great Yarmouth], Queen Elizabeth II Hospital (King's Lynn), and West Suffolk Hospital (Bury St. Edmunds)], and Gastroenterology Directorate of Norfolk and Norwich NHS Health Care Trust. Dr. Canoy acknowledges studentship received from Shell Centenary Scholarship through Cambridge Overseas Trust.

Submitted June 6, 2001. Accepted after revision October 24, 2001.
Background. Studies on the incidence of perforated duodenal ulcer are limited and in the United Kingdom, data are largely based on findings observed over two decades ago. To provide updated epidemiological data on duodenal ulcer perforation, the incidence of the disease in Norfolk, United Kingdom was determined.

Methodology. Medical records of patients with duodenal ulcer perforation were reviewed to confirm the diagnosis and obtain information on possible risk factors, namely, Helicobacter pylori infection, smoking and intake of non-steroidal anti-inflammatory drugs. The patients were admitted between 1 January 1996 and 31 December 1998, and were residents of Norfolk, United Kingdom.

Results. Sixty-eight cases of duodenal ulcer perforation were identified, 36 [52.9\%] were males and 32 (47.1\%) were females. The agestandardised incidence rate was 3.77 per 100,000 population per year (95\% confidence interval 3.72-3.83). The mean age upon admission for all cases was 72.3 years (standard deviation: 17.8). The mean age for males was 67.7 years (standard deviation: 19.4) and for females 77.6 years (standard deviation: 15.7), which differed significantly (difference in means: 9.9, 95\% confidence interval 1.518.3]. There were 29 deaths [42.7\%], of which 19 were females. After adjustment for covariates, the odds ratio of mortality in women was 4.57 [95\% confidence interval 1.28-16.29]. There were 25 [36.8\%] smokers and 22 (32.4\%) patients were non-steroidal anti-inflammatory drug users. Helicobacter pylori infection was assessed in only 14 (20.6\%) patients; 2 were positive, 3 were negative, and in the rest the results were unrecorded.

Conclusions. The incidence rates were lower compared to previous studies in the United Kingdom conducted in the 1960's and 1980's, which could reflect either improved health care or decreasing exposure to known risk factors. Furthermore, the difference in age distribution of incident cases between males and females may explain the higher mortality in females.

\section{Digest Liver Dis 2002;34:322-7}

Key words: duodenal ulcer perforation; Helicobacter pylori; non-steroidal anti-inflammatory drugs; smoking

\section{Introduction}

Although there is a decreasing trend in incidence ${ }^{1-7}$, perforated duodenal ulcer remains a serious condition which generally requires surgical intervention, and is associated with a high mortality rate especially among the elderly ${ }^{6-10}$. Various risk factors, such as smoking, use of non-steroidal anti-inflammatory drugs (NSAIDs) and Helicobacter pylori (H. pylori), have been implicated but data remain inconclusive. However, before any further epidemiological investigation is done, there is a need to determine more accu- 
rate estimates of the incidence of duodenal ulcer perforation in the population. In the United Kingdom, the epidemiological data on perforated duodenal ulcers have, until now, been largely based on studies conducted about two decades ago ${ }^{67}$. Hence, the aims of the study are to provide an updated population-based incidence rate of perforated duodenal ulcers and investigate the prevalence of factors that may be associated with the development of this disease.

\section{Material and methods}

The study was conducted on the population living in the Norfolk postcode areas NR 1-31. The local population demographic data based on the postcodes were obtained from the Census Dissemination Unit ${ }^{11}$. There were four hospitals to which patients could potentially be referred; the Norfolk and Norwich Health Care NHS Trust (Norwich), the James Paget Hospital Healthcare Trust (Great Yarmouth), the Queen Elizabeth II Hospital (King's Lynn), and the West Suffolk Hospital (Bury St. Edmunds). Approval of both the relevant ethics committee and consultants of each hospital were obtained. The Trust's Statistics and Information Departments were asked to identify cases of perforated duodenal ulcers, using ICD-10 ${ }^{12}$, admitted between 1 January 1996 and 31 December 1998. The medical records of all identified patients were reviewed to confirm diagnosis and obtain demographic data. The following information was also recorded: $H$. pylori status (including type of test used and results of tests), smoking (whether "current," "former" or "never" smokers), NSAID use, and history of peptic ulcer disease.

$\Lambda \mathrm{n}$ identified case was included if it had one or more of the following criteria: 1 . visualisation of a duodenal ulcer perforation at endoscopy or surgery; 2 . surgical identification of a sealed perforation of a duodenal ulcer, with pus or abscess in the abdominal cavity indicating a recent perforation; 3 . identification of a perforated duodenal ulcer based on pathology reports. Cases based on clinical or radiological findings alone without a confirmatory surgery or pathology report, or those who had a previous history of duodenal ulcer perforation, were excluded. Mortality was considered related to the perforation when medical records showed that the perforation was either the primary cause or contributory factor to the demise of the patient.

The crude and standardised incidence and mortality rates of perforated duodenal ulcer were calculated both for males and females using a direct standardisation method ${ }^{13}$. The mid-1997 population estimate of England and Wales was used as the standard population ${ }^{14}$. Differences in means and in proportions were tested using $t$ test and chi-square test, respectively. Linear lo- gistic regression was used to compute for odds ratios, and result cstimatc was set at $95 \%$ confidence interval (CI). In the regression analyses, we assigned null values for some of the variables with inadequate information. Hence, the referent group used in the regression models for each variable of interest (cigarette smoking status, NSAID use and history of peptic ulcer disease) was composed of 'never smokers', non-NSAID users and no previous peptic ulcer disease and those with missing information for each of the variables. We did not include $H$. pylori status in the regression due to the very small number of cases in whom the $H$. pylori test was carried out. Cases were also divided according to three age groups (under 65 years, 65 to 74.9 years and 75 years or older), and the lowest age group formed the referent group. The statistical software package used was STATA 6.

\section{Results}

During the 36-month study period, 84 possible cases were identified, but for four of these, records were not available for review and these cases were subsequently excluded from the analysis. A further 12 cases were excluded: no surgical, endoscopic or pathology report confirmation (4 cases), in which cases diagnosis was based on radiographic evidence (4 cases) or clinical findings only ( 3 cases), or miscoded ( 1 case). The remaining 68 cases $[36(52.9 \%)$ males and $32(47.1 \%)$ females] were included.

The total crude incidence in Norfolk was 4.27 cases per 100,000 population per year $(95 \%$ CI $3.37-5.41)$ (Table I) while the age- and sex-standardised incidence rate cases were 3.77 (95\% CI 3.72-3.83) pcr 100,000 population per year. The mean age of all cases was 72.3 years [standard deviation $(\mathrm{SD})=17.8$ ) and men were significantly younger than women $(67.7$ years $[S D=19.4]$ for men and 77.6 years $[S D=15.71$ for women; difference in means $=9.9$ [95\% CI 1.5-18.3]). The crude as well as the age-standardised incidence rates in men were higher than those in women.

Twenty-nine $(42.7 \%)$ patients died, 24 due to complications of the perforation. The total crude mortality rate was 1.82 (95\% CI 1.26-2.61) per 100,000 population per year. The mortality rate in women was higher than in men. The mean age of those who died was 77.9 years $(\mathrm{SD}=14.4)$. For men, it was 78.1 years $(\mathrm{SD}=12.2)$ and for women, it was 77.7 years $(\mathrm{SD}=15.7)$. The age difference was not significant (difference in means $=0.40,95 \% \mathrm{CI}-11.4-12.1$ ). Of the 29 deaths, $19(65.5 \%)$ were women. The mean age for men who survived $[63.7$ years $(\mathrm{SD}=20.3)]$ compared to those who died [78.1 years $(\mathrm{SD}=12.2)]$ was significantly different (difference in means $=14.4,95 \% \mathrm{CI}$ 
Table I. Rates for duodenal ulcer perforation cases in Norfolk per 100,000 population per year, between 1996-1998.

\begin{tabular}{|c|c|c|c|c|c|c|}
\hline \multirow{2}{*}{$\begin{array}{l}\text { Age group } \\
\text { (years) }\end{array}$} & \multicolumn{2}{|c|}{ Males $[n]$} & \multicolumn{2}{|c|}{ Females $[\boldsymbol{n}]$} & \multicolumn{2}{|c|}{ Total $[n]$} \\
\hline & Incident cases & Mortality & Incident cases & Mortality & Incident cases & Mortality \\
\hline $\begin{array}{l}0-29 \\
30-39 \\
40-49 \\
50-59 \\
60-69 \\
70-79 \\
80+ \\
\text { All ages }\end{array}$ & $\begin{array}{r}3 \\
1 \\
3 \\
3 \\
5 \\
10 \\
11 \\
36\end{array}$ & $\begin{array}{r}0 \\
0 \\
1 \\
0 \\
1 \\
3 \\
5 \\
10\end{array}$ & $\begin{array}{r}1 \\
0 \\
1 \\
0 \\
1 \\
12 \\
17 \\
32\end{array}$ & $\begin{array}{r}1 \\
0 \\
0 \\
0 \\
0 \\
8 \\
10 \\
19\end{array}$ & $\begin{array}{r}4 \\
1 \\
4 \\
3 \\
6 \\
22 \\
28 \\
68\end{array}$ & $\begin{array}{r}1 \\
0 \\
1 \\
0 \\
1 \\
11 \\
15 \\
29\end{array}$ \\
\hline $\begin{array}{l}\text { Crude rate } \\
\text { [95\% Cl] }\end{array}$ & $\begin{array}{l}4.65 \\
\text { (3.35-6.43) }\end{array}$ & $\begin{array}{l}1.29 \\
(0.70-2.38)\end{array}$ & $\begin{array}{l}3.91 \\
(2.76-5.52)\end{array}$ & $\begin{array}{l}2.32 \\
\text { (1.48-3.62) }\end{array}$ & $\begin{array}{l}4.27 \\
{[3.37-5.41]}\end{array}$ & $\begin{array}{l}1.82 \\
(1.26-2.61)\end{array}$ \\
\hline $\begin{array}{l}\text { Standardised rate } \\
\text { (95\% Cl) }\end{array}$ & $\begin{array}{l}4.86 \\
\text { (4.79-4.93) }\end{array}$ & $\begin{array}{l}1.42 \\
(0.94-2.14)\end{array}$ & $\begin{array}{l}2.86 \\
(2.82-2.90)\end{array}$ & $\begin{array}{l}1.70 \\
(1.13-2.56)\end{array}$ & $\begin{array}{l}3.77 \\
\text { (3.72-3.83) }\end{array}$ & $\begin{array}{l}1.58 \\
(1.05-2.38)\end{array}$ \\
\hline
\end{tabular}

Standard error: (pq/n):1/2 ' Standardised to total population of England \& Wales (1997 mid-year estimate) ${ }^{13}$. Abbreviations: see list.

Table II. Distribution of characteristics by survival status of males and females admitted for duodenal ulcer perforation in Norfolk, United Kingdom, 1996-1998.

\begin{tabular}{lccc}
\hline $\begin{array}{l}\text { Survival } \\
\text { status }\end{array}$ & $\begin{array}{c}\text { NSAID } \\
\text { users }\end{array}$ & $\begin{array}{c}\text { Cigarette } \\
\text { smokers N (\%) }\end{array}$ & $\begin{array}{c}\text { Peptic ulcer } \\
\text { disease }\end{array}$ \\
\hline $\begin{array}{l}\text { Males }(\mathrm{N}=36) \\
\text { Survived }\end{array}$ & $4(80.0)$ & $11(61.1)$ & $4(50.0)$ \\
Died & $1(20.0)$ & $7(38.9)$ & $4(50.0)$ \\
All males & $5(100.0)$ & $18(100.0)$ & $8(100.0)$ \\
Female (N=32) & & & \\
Survived & $8(47.0)$ & $5(71.4)$ & $1(50.0)$ \\
Died & $9(53.0)$ & $2(28.6)$ & $1(50.0)$ \\
All females & $17(100.0)$ & $7(100.0)$ & $2(100.0)$ \\
\hline
\end{tabular}

Abbreviations: see list.
0.4-28.5). However, the mean age for women who survived [77.3 years $(\mathrm{SD}=12.7)]$ compared to those who died $[77.7$ ( $\mathrm{SD}=15.7)]$ was not significantly different (difference in means $=0.4,95 \% \mathrm{CI}-11.2-10.3)$.

There were only $14(21.5 \%)$ records which showed that the $H$. pylori status had been tested for. Two cases were positive and three were negative, and the rest of those tested had no record of the results. Twenty-five patients $(36.8 \%)$ had smoked cigarettes in the past and $22(32.4 \%)$ were users of NSAIDs. Two out of 4 cases under 30 years of age had a history of substance abuse but information on the specific substances used was unavailable. Ten $(14.7 \%)$ cases showed prior history of peptic ulcer disease. Table II shows the distribution of some of these characteristics in males and females who had perforated duodenal ulcers.

Table III shows the odds ratios for various factors that could influence mortality rates. The odds ratio of mor-

\begin{tabular}{|c|c|c|c|c|}
\hline \multirow[t]{2}{*}{ Variables } & \multicolumn{2}{|c|}{ Univariate regression model ${ }^{\circ}$} & \multicolumn{2}{|c|}{ Multivariate regression model ${ }^{28}$} \\
\hline & Odds ratio & $95 \%$ CI & Odds ratio & $95 \%$ CI \\
\hline Sex (females vs males) & 3.80 & $1.38-10.48$ & 4.57 & $1.28-16.25$ \\
\hline Age group & 2.30 & $1.15-4.64$ & 2.22 & $1.00-4.95$ \\
\hline NSAID use & 1.18 & $0.43-3.30$ & 0.42 & $0.11-1.62$ \\
\hline Smokers (ever vs never) & 0.65 & $0.23-1.78$ & 1.07 & $0.34-3.41$ \\
\hline Known peptic ulcer disease & 1.42 & $0.37-5.44$ & 1.63 & $0.33-8.05$ \\
\hline
\end{tabular}

Abbreviations: see list; " separate logistic regression models were used for each variable; " all variables were included as terms in logistic regression model; “" age group treated as continuous variable. 
tality occurring in women was 3.80 (95\% CI 1.38$10.48)$ and the age-adjusted odds ratio was $3.06(95 \%$ CI 1.06-8.78). The odds ratio for age group when this was treated as a continuous variable was $2.30(95 \% \mathrm{CI}$ 1.15-4.64). Use of NSAIDs, cigarette smoking and previously known peptic ulcer disease had confidence intervals including 1 . In the multivariate analyses, the odds of mortality of being female increased to 4.57 (95\% CI 1.28-16.29) despite adjusting for age, NSAID use, cigarette smoking and known history of peptic ulcer disease. The odds ratio for age decreased to just below the significance value, whereas the rest of the covariates remaincd non significant. Stratifying by sex, multivariate analyses showed that the odds ratio for age in men was 3.38 (95\% CI 1.11-10.27) and in women was 1.15 (95\% CI 0.29-4.61). The remaining variables remained non significant.

\section{Discussion}

This study found the crude incidence of duodenal ulcer perforation to be 4.27 per 100,000 population per year in Norfolk. The age-standardised incidence of perforation in Norfolk is higher compared to that in the United States and Finland, but lower than that in Hong Kong ${ }^{15}$ (Table IV) and in previous reports from the United Kingdom ${ }^{67816}$. The decreasing trend in the incidence of perforated duodenal ulcers may be partly explained by the improved health care or reflect decreasing exposure to environmental factors, such as smoking, diet and other aspects of lifestyle.

In this study, the incidence rate was higher among men. Other studies have shown that the male to female ratio of the number of cases has been decreasing over-

\begin{tabular}{|c|c|c|}
\hline Study & Time period & $\begin{array}{c}\text { Rate per } 100,000 \\
\text { per year }\end{array}$ \\
\hline $\begin{array}{l}\text { United Kingdom } \\
\text { Oxford }{ }^{8} \\
\text { North East Scotland }{ }^{16} \\
\text { Norfolk }\end{array}$ & $\begin{array}{l}1965-1970 \\
1971-1976 \\
1977-1982 \\
1977-1980 \\
1996-1998\end{array}$ & $\begin{array}{l}8.1 \\
8.7 \\
6.9 \\
9.8 \\
3.77\end{array}$ \\
\hline United States ${ }^{1}$ & $1970-1978$ & 1.14 \\
\hline United States ${ }^{2}$ & 1970-1978, 1980 & 3.2 \\
\hline Hong Kong ${ }^{15}$ & $1970-1980$ & 11.5 \\
\hline Finland ${ }^{3}$ & 1987 & 2.0 \\
\hline
\end{tabular}

all. In England and Wales, this ratio was 6:1 between 1958-1962 and decreased to $2: 1$ in $1978-82^{7}$. In Norfolk, this ratio was $1.2: 1$. It has been argued that this decreasing trend in the ratio was also accounted for by the increase in cases in women ${ }^{4}$.

The increasing incidence in the elderly is consistent with the trends noted in previous studies in the United Kingdom ${ }^{67}$. Mortality at $42.7 \%$ was much higher than that observed in another study, where only $11.4 \%$ (17 out of 149 cases) died ${ }^{8}$. But the mean age of cases in the latter was lower than that in Norfolk. However, the preponderance of mortality in the older age group observed in Norfolk was also seen in other studies ${ }^{7} 1718$. In our study, women tended to be more likely to die than men with this condition. Adjusting for other covariates (H. pylori status was not included because of limited data), sex remained an important variable that was associated with mortality. The effect of age also seemed important in the univariate analysis but only approaching significance in the multivariate regression model. Stratifying the effect of age by sex, the odds ratio for age in men became significant but this was not the case in women. This was reflected in the difference in the mean age of men who survived from those who died, which was not observed in women. Hence, the effect of sex may be explained by the sex difference in the age distribution of the incidence of the disease. This sex difference in age distribution probably explains the increasing mortality in women in other studies $^{7}$. It has also been suggested that the wider use of antacids in a population was associated with a decreased incidence of perforated duodenal ulcers in the younger age group but resulted in increasing incidence in the older age groups ${ }^{35}$. The role of antacid intake particularly among women was not investigated bccause such data were not readily available.

Among the risk factors for duodenal ulcer perforation, the role of $H$. pylori, smoking and use of NSAIDs have been investigated. Studies investigating the relationship of $H$. pylori and duodenal ulcer perforation have given conflicting results ${ }^{19-22}$. Furthermore, no epidemiological studies have shown any association between $H$. pylori and perforated duodenal ulcer development when other risk factors such as age, sex, NSAID use and smoking were adjusted for. In our study, only $21.5 \%$ of cases had been tested for $H$. pylori. Clcarly, this would need to be improved if future aetiological investigations are considered.

The effect of smoking needs further investigation. Cigarette smoking status (current versus former) as well as quantification of duration and number of cigarettes used was difficult to identify from the medical records. In one case-control study, smoking prevalence was higher among cases of duodenal ulcer perforation ( $86 \%$ of 128 cases) compared to the control group 
(51\% of 128 cases) ${ }^{23}$. The prevalence of smoking among the cases in Norfolk at $36.8 \%$ was lower, but this may be because in the case-control study, cases were identified from among those who already had prior peptic ulcer disease and subsequently admitted for emergency treatment for perforation.

Older patients may be particularly at higher risk of NSAID gastropathy ${ }^{24}$. However, the role of NSAIDs in the development of perforated duodenal ulcers has been based largely on ecological associations or retrospective reviews of medical records and has given conflicting results ${ }^{25-27}$. The prevalence of NSAID use among perforated cases of the duodenum from Norfolk at $32.4 \%$ was similar to a study involving hospitalidentified cases (32\% of 217 cases) ${ }^{26}$ but higher compared to cases identified by a health management organisation (12.5\% of 48 cases) ${ }^{27}$. Availability and access to information on NSAID use as well as the population from which cases were identified may explain these differences in NSAID use prevalence. Use of cocaine has been associated with developing perforation of the duodenum in the younger age group ${ }^{28}{ }^{29}$. Two of the four cases in Norfolk who were below 30 years of age had exposure to substances of abuse prior to the occurrence of perforation. However, the specific substance used could not be verified.

As perforated duodenal ulcer is a mandatory cause for admission, the use of hospital records could be relied upon as a reasonably accurate and readily available source of information. The accuracy of the study was increased by searching for cases living in Norfolk, but who were seen in other hospitals just outside the study area. Cases in patients who died in other health care settings could have been missed. However, these patients would probably have had post-mortem reports, which are routinely incorporated in the hospital medical records and, therefore, the statistics department should have been notified. It could also be argued that our case ascertainment method excluded patients managed conservatively. Hence, the incidence in Norfolk reported here is likely to slightly underestimate the true incidence since cases diagnosed solely on radiologic or clinical findings, without surgical or pathological confirmation, were excluded. However, we searched for these cases in the hospital data and found seven such cases, which would only result in an increase of our incidence rate estimate by 0.44 per 100,000 population per year.

This study has provided an updated epidemiological description of the number and characteristics of cases of duodenal ulcer perforation. With the recent incidence of duodenal ulcer perforation now determined, the size of the population and duration of years needed to accumulate enough cases for future epidemiological investigation can now be estimated. For example, in the "Norfolk population" of about 500,000 people, a study needs at least 5 ycars of follow-up to accrue 100 cases. The role of cigarette smoking and NSAID use need further investigation to clarify if they are important risk factors. However, more detailed information should be gathered on the amount and duration of use both of cigarettes and drugs. It would also be useful to collect data on antacid use and determine underlying peptic ulcer disease among cases. The role of $H$. pylori status in perforation also needs to be determined. Further investigations should also look at factors that would explain the age difference in the incidence of the disease between the sexes, which was shown to be an important determinant of the associated mortality. Hopefully, these future investigations would lead to measures to reduce the incidence and mortality of this serious condition.

\section{List of ahbreviations}

Cl: confidence interval; $H$. pylori: Helicobacter pylori; NSAIDs: nonsteroidal anti-inflammatory drugs; SD: standard deviatiurı.

\section{References}

${ }^{1}$ Elashoff J, Grossman M. Trends in hospital admission and death rates for peptic ulcer in the United States from 1970 to 1978. Gastroenterology 1980;78:280-5.

${ }^{2}$ Kurata J, Honda G, Frankl H. Hospitalization and mortality rates for peptic ulcers: A comparison of a large Health Maintenance Organization and United States Data. Gastroenterology 1982;83:1008-16.

${ }^{3}$ Paimela, H, Tuompo P, Perakyla T, Saario I, Hockerstedt K, Kivilaakso E. Peptic ulcer surgery during the $\mathrm{H}_{2}$-receptor antagonist era: a population-based epidemiological study of ulcer surgery in Helsinki from 1972 to 1987. Br J Surg 1991;78:28-31.

${ }^{4}$ Svanes C, Lie R, Kvale G, Svanes K, Soeride O. Incidence of perforated ulcer in Western Norway, 1935-1990: Cohort- or Perioddependent time trends? Am J Epidemiol 1995;141:836-44.

${ }^{5}$ Hermansson M, Holstein C, Zilling T. Peptic ulcer perforation before and after the introduction of $\mathrm{H}_{2}$-receptor blockers and proton pump inhibitors. Scand J Gastroenterol 1997;32:523-9.

${ }^{6}$ Coggon D, Lambert P, Langman M. 20 years of hospital admissions for peptic ulcer in England and Wales. Lancet 1981;i:13024.

${ }^{7}$ Walt R, Katschinski B, Logan R, Ashley J, Langman M. Rising frequency of ulcer perforation in elderly people in the United Kingdom. Lancet 1986; :489-92.

${ }^{8}$ Watkins R, Dennison A, Collin J. What has happened to perforated peptic ulcer? Br J Surgery 1984;71:774-6.

${ }^{9}$ Svanes C, Salvesen H, Stangeland L, Svanes K, Soreide O. Perforated peptic ulcer over 56 years. Time trends in patients and disease characteristics. Gut 1993;34:1666-71.

${ }^{10}$ Gustavsson S, Kelly K, Melton L, Zinsmeister A. Trends in peptic ulcer surgery. Gastroenterology 1988;94:688-94.

${ }^{11}$ Census Dissemination Unit. Small area and local base statistics from the 1991 census for Great Britain and Northern Ireland. Manchester: The University of Manchester, 1995. 
12 World Health Organization. International Statistical Classification of Diseases and Related Health Problems, 10th Ed. Geneva: World Health Organization; 1992.

13 OPCS Monitor, PP1 94/1. London: HMSO; 1994.

it Smith PG. Comparison between registries: Age-standardized rates. In: Parkin DM, Muir CS, Whelan SL, Gao YT, Ferlay J, Powell J, editors. Cancer incidence in five continents, Vol VI. Lyon: International Agency for Research on Cancer; 1992.

${ }^{15}$ Koo J, Ngan Y, Lam S. Trend in hospital admission, perforation, and mortality of peptic ulcer in Hong Kong from 1970 to 1980. Gastroenterology 1983;84:1558-62.

16 Valerio D. Hendry W, Kyle J. Gastroduodenal perforation in North East Scotland, 1972-81; a rise in incidence. Gastroenterology 1982;83:T19-30.

${ }^{17}$ Irvin T. Mortality and perforated peptic ulcer: a case for risk stratification in elderly patients. Br J Surg 1989;76:215-8.

${ }^{18}$ Paimela H. Joutsi T, Kiviluoto T, Kivikaakso E. Recent trends in mortality from peptic ulcer disease in Finland. Dig Dis Sci 1995;40:631-5.

${ }^{19}$ Sebastian M, Chandran V, Elashaal Y, Sim A. Helicobacter pylori infection in perforated peptic ulcer disease. $\mathrm{Br} \mathrm{J}$ Surg 1995;82:360-2.

21) Ng E, Chung S, Sung J, Lam Y, Lee D, Lau J, et al. High prevalence of Helicobacter pylori infection in duodenal ulcer perforations not caused by non-steroidal anti-inflammatory drugs. $\mathrm{Br} \mathrm{J}$ Surg 1996:83:1779-81.
${ }^{21}$ Reinbach D, Cruickshank G, McColl K. Acute perforated duodenal ulcer is not associated with Helicobacter pylori infection. Gut 1993;34:1344-7.

22 Matsukura N, Onda $M$, Tokunaga A, Kato S, Yoshiyuki T, Hasegawa $\mathbf{H}$, et al. Role of Helicobacter pylori infection in perforation of peptic ulcer: An age- and gender-matched case-conrol study. J Clin Gastroenterol 1997;25(Suppl 1):S235-9.

${ }^{23}$ Smedley F, Hickish T, Taube M, Yale C, Leach R, Wastell C. Perforated duodenal ulcer and cigarette smoking. J Roy Soc Med 1988;81:92-4.

${ }^{24}$ Russell R. Defining patients at risk of non-steroidal anti-inflammatory drug gastropathy. Ital J Gastroenterol Hepatol 1999;31(Suppl 1):S14-8.

${ }^{25}$ Langman M. Ulcer complications and nonsteroidal anti-inflammatory drugs. Am J Med 1988;84:15-9.

${ }^{26}$ Collier D, Pain J. Ulcer perforation in the elderly and nonsteroidal anti-inflammatory drugs. Lancet 1986;i:971-2.

${ }^{27}$ Jick S, Perera D, Walker A, Jick H. Non-steroidal anti-inflammatory drugs and hospital admission for perforated peptic ulcer. Lancet 1987;ii:380-2.

${ }^{28}$ Lee H, Lamaute H, Pizzi W, Picard D, Luks F. Acute gastroduodenal perforation associated with use of crack. Ann Surg 1990;211:15-17.

${ }^{29}$ Sharma R, Organ C, Hirvela E, Henderson V. Clinical observation of the temporal association between crack cocaine and duodenal ulcer perforation. Am J Surg 1997;174:629-33.

\title{
SECOND Edition Symposium:
}

\section{FEMALE GENDER AND LIVER: HORMONAL, GENETIC, METABOLIC, AND IMMUNOLOGIC FACTORS IN LIVER DAMAGE}

\author{
L'Aquila (Italy), September 2003 \\ (date to be arranged)
}

For further information please contact:

Scientific Committee:

Prof. A. Floreani, Prof. M. Chiaramonte, Prof. D. Minnucci

Phone +39-049-8212894/+39-0862-3686525 - Fax: +39-049-8760820/+39-0862-404561

E-mail: annarosa.floreani@unipd.it - chiaramontemaria@tin.it 